\title{
Proceeding Paper \\ Experimental Investigation of Iodine Removal in a Submerged Venturi Scrubber ${ }^{+}$
}

\author{
Jawaria Ahad ${ }^{1, *}$, Amjad Farooq ${ }^{1}$, Masroor Ahmad ${ }^{1}$, Khalid Waheed ${ }^{1}$, Kamran Rasheed Qureshi ${ }^{2}$, \\ Waseem Siddique ${ }^{2}$ and Naseem Irfan ${ }^{1}$ \\ 1 Department of Nuclear Engineering, Institute of Engineering and Applied Sciences, \\ Islamabad 45650, Pakistan; amjad@pieas.edu.pk (A.F.); mahmad@pieas.edu.pk (M.A.); \\ khalidwaheed@pieas.edu.pk (K.W.); naseem@pieas.edu.pk (N.I.) \\ 2 Department of Mechanical Engineering, Institute of Engineering and Applied Sciences, \\ Islamabad 45650, Pakistan; k.qureshi@pieas.edu.pk (K.R.Q.); waseem@pieas.edu.pk (W.S.) \\ * Correspondence: jawariahad@gmail.com \\ + Presented at the 1st International Conference on Energy, Power and Environment, Gujrat, Pakistan, \\ 11-12 November 2021.
}

check for updates

Citation: Ahad, J.; Farooq, A.; Ahmad, M.; Waheed, K.; Qureshi, K.R.; Siddique, W.; Irfan, N. Experimental Investigation of Iodine Removal in a Submerged Venturi Scrubber. Eng. Proc. 2021, 12, 38. https://doi.org/10.3390/ engproc2021012038

Academic Editor: Muhammad Tanveer

Published: 27 December 2021

Publisher's Note: MDPI stays neutral with regard to jurisdictional claims in published maps and institutional affiliations.

Copyright: (C) 2021 by the authors. Licensee MDPI, Basel, Switzerland. This article is an open access article distributed under the terms and conditions of the Creative Commons Attribution (CC BY) license (https:/ / creativecommons.org/licenses/by/ $4.0 /)$.

\begin{abstract}
Severe nuclear accidents can cause over-pressurization and serious damage to the containment of a nuclear power plant, which can result in the release of radioactivity into the environment. Filtered containment venting systems are a nuclear safety system that is designed to control overpressurization and prevent radioactive fission products from spreading into the environment in the case of a severe accident. Iodine is one of the most harmful products among this list of fissionable products, as it can cause thyroid cancer. The removal of iodine is very important in order to ensure the safety of people and the environment. Thus, an indigenous lab scale setup of this system was developed at PIEAS to conduct research on iodine removal. It is comprised of a compressor for replicating high-pressure accident scenarios, a heater to keep iodine in a vapor form, a dosing pump for the injection of iodine, and a venturi scrubber, submerged in the scrubbing column, containing a solution of $0.2 \%$ sodium thiosulphate and $0.5 \%$ sodium hydroxide. Inlet and outlet samples were trapped in $0.1 \mathrm{M} \mathrm{KOH}$ solution and analyzed via UV-VIS spectroscopy. Operating parameters play an important role in the working of a venturi scrubber. The throat velocity was varied to determine its influence on the removal efficiency of iodine. An increase in removal efficiency was observed with an increase in throat velocity. A removal efficiency of $>99 \%$ was achieved, which fulfilled the requirements for FCVS.
\end{abstract}

Keywords: environmental safety; iodine removal; hazardous gas removal; nuclear power plants; venturi scrubbers

\section{Introduction}

Nuclear power plants are reliable sources of energy. They are comprised of very specific design with a wide range of safety margins. The safety systems of nuclear power plants are well able to handle design-based accidents. However, after major nuclear accidents, such as TMI, Chernobyl, and Fukushima, many concerns have been raised regarding the safety of people and the environment in case a beyond-design-based accident takes place. In a severe accident scenario, containment pressure can surpass the allowable limit of pressure; this can lead to ruptures or explosions, resulting in the spread of radioactivity into environment. Thus, extensive research has been conducted on safety systems for beyond-design-based accidents [1] and a system named the filtered containment venting system (FCVS) was suggested as a solution to this problem. Main objective of this system was to protect the integrity of containment of a power plant and prevent radioactivity from spreading out into the environment. FCVS controls excessive pressure by transferring part of containment air into this system [2]. It cannot be released directly into the environment 
as it contains radioactive products. Iodine, being one of most volatile and toxic radioactive products, can cause thyroid cancer; thus, its removal is necessary for the safety of people. This system contains a group of scrubbers for the removal of radioactivity from containment air, and clean air is then vented out. Scrubbers play an important role in this system. Various types of scrubbers have been used, but venturi scrubbers are the most popular from this list because of their high efficiency. Venturi scrubbers are available in two modes, self priming and forced feed. In the forced feed mode, water is supplied to the throat or the converging section via a pump, while, in the self-priming mode, the water gets automatically injected into the throat of a venturi via orifices due to the pressure gradient between the inner and outer throats [3,4]. Operational parameters play an important role in performance of a venturi scrubber. In this study, the throat gas velocity was varied to determine its effect on the removal efficiency of iodine.

\section{Materials and Methods}

A schematic diagram of the experimental setup is shown in Figure 1. High pressure in a severe accident scenario was imitated using compressed air from a compressor. Compressed air was then passed through a moisture separator to strip out moisture and a rotameter was used to control the flowrate. Air was then heated using an air heater over the sublimation temperature of iodine. This heated air was mixed with iodine that was being inserted using an injection pump. This air and gas mixture was then added into a scrubbing column. The scrubbing column was comprised of a venturi scrubber submerged in a scrubbing solution of $0.2 \%$ sodium thiosulphate and $0.5 \%$ sodium hydroxide. The retention of iodine took place in the column. Outlet samples were taken from the exit of the column. Samples were analyzed using UV-VIS spectroscopy to estimate the retention efficiency of iodine.

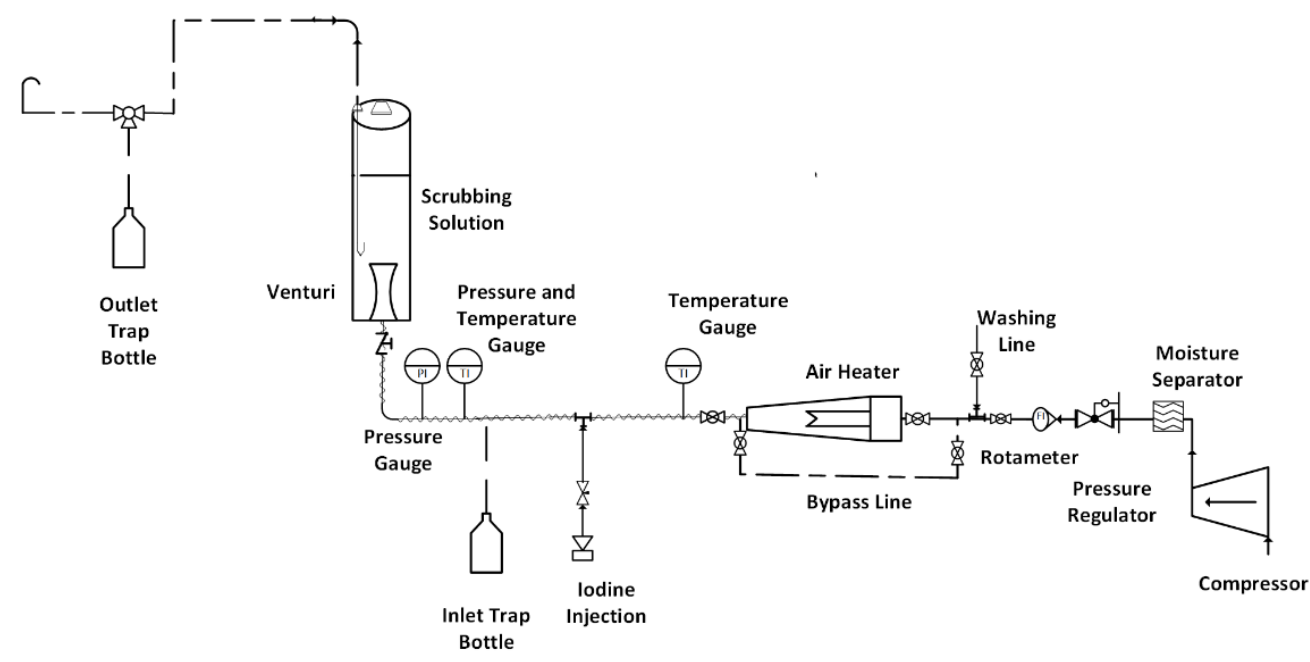

Figure 1. Schematic diagram of FCVS setup.

\section{Results and Discussion}

A venturi scrubber submerged in a scrubbing column was used for iodine removal. The gas-air mixture entered the venturi scrubber via a converging section. As it moved along, the velocity of the gas increased due to the decrease in area and, as a result, the pressure decreased as well. When it got to the throat region, negative pressure was achieved. Due to the difference in pressure between the inner and outer throats, liquid from the column was injected into the throat via orifices [5]. On contact with gas, it disintegrated into small droplets due to inertial impaction. Mass transfer between the gas and liquid took place and iodine was removed In this study, the throat gas velocity was varied at $2.5 \mathrm{ft}$. head to determine its effect on removal efficiency of iodine, as shown in Figure 2. An increase in removal efficiency was observed with an increase in the throat gas velocity. When the throat gas velocity increased, the gas flow rate increased as well. Due to increase 
in the gas flow rate, more gas-liquid contact took place and inertial impaction increased as well. A smaller number of droplets were produced, which increased the surface of contact, as such the mass transfer increased. As a result, more iodine was removed and the removal efficiency of iodine increased.

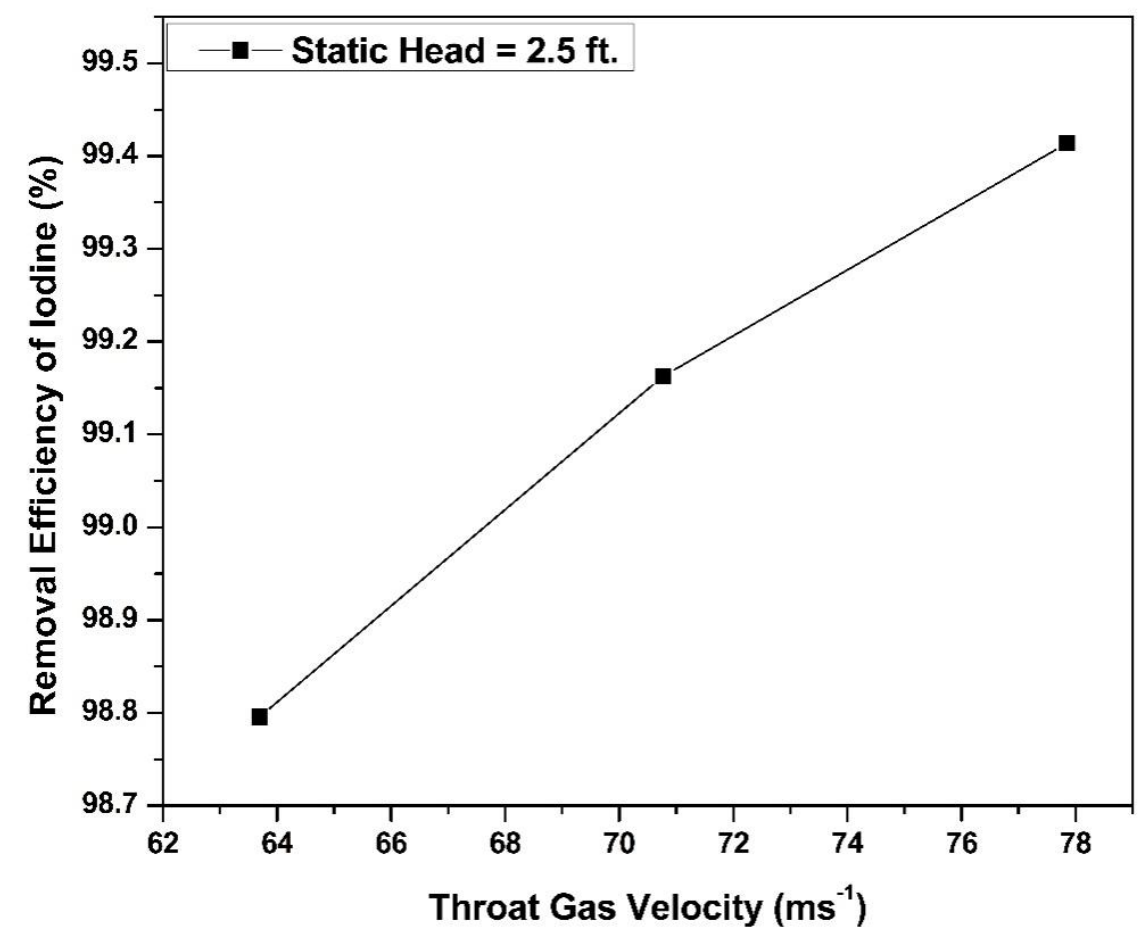

Figure 2. Effect of throat gas velocity on removal efficiency.

\section{Conclusions}

The increase in removal efficiency was observed with an increase in throat gas velocity. Overall, a >99\% maximum removal efficiency was obtained, which fulfilled the requirement for FCVS.

Author Contributions: J.A.: data curation, formal analysis, writing-original draft. A.F.: conceptualization, supervision, writing —original draft, funding acquisition. K.W.: conceptualization, writingoriginal draft. M.A.: conceptualization, writing-review and editing. K.R.Q.: writing-review and editing N.I.: supervision, conceptualization, funding acquisition. W.S.: project administration. All authors have read and agreed to the published version of the manuscript.

Funding: This research received no external funding.

Acknowledgments:

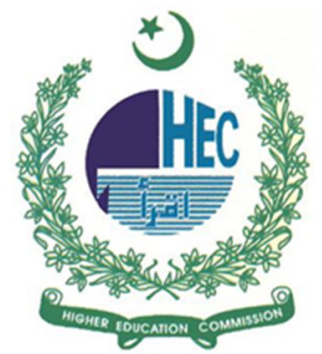

Conflicts of Interest: The authors declare no conflict of interest. 


\section{References}

1. Jacquemain, D.; Guentay, S.; Basu, S.; Sonnenkalb, M.; Lebel, L.; Ball, J.; Allelein, H.J.; Liebana Martinez, B.; Eckardt, B.; Losch, N.; et al. OECD/NEA/CSNI status Report on filtered Containment Venting; Organisation for Economic Co-Operation and Development: Paris, France, 2014.

2. Solaija, T.; Irfan, N.; Qureshi, K.; Waheed, K.; Farooq, A.; Ahmad, M. (Eds.) Filtered Containment Venting System (FCVS) for removal of elemental and organic iodine during severe nuclear power plant accidents. In Proceedings of the 2017 3rd International Conference on Power Generation Systems and Renewable Energy Technologies (PGSRET), Johor Bahru, Malaysia, 4-6 April 2017; IEEE: New York, NY, USA, 2017.

3. Ali, S.; Waheed, K.; Qureshi, K.; Irfan, N.; Ahmed, M.; Siddique, W.; Farooq, A. Experimental investigation of aerosols removal efficiency through self-priming venturi scrubber. Nucl. Eng. Technol. 2020, 52, 2230-2237. [CrossRef]

4. Ali, M.; Yan, C.; Sun, Z.; Gu, H.; Wang, J. Study of iodine removal efficiency in self-priming venturi scrubber. Ann. Nucl. Energy 2013, 57, 263-268. [CrossRef]

5. Jung, J.; Lee, J.B.; Kim, H.Y. (Eds.) Experimental Investigation of Iodine Decontamination Performance of a Filtered Containment Venting System in ARIEL Facility. In Proceedings of the 26th International Conference Nuclear Energy for New Europe, Bled, Slovenia, 11-14 September 2017. 